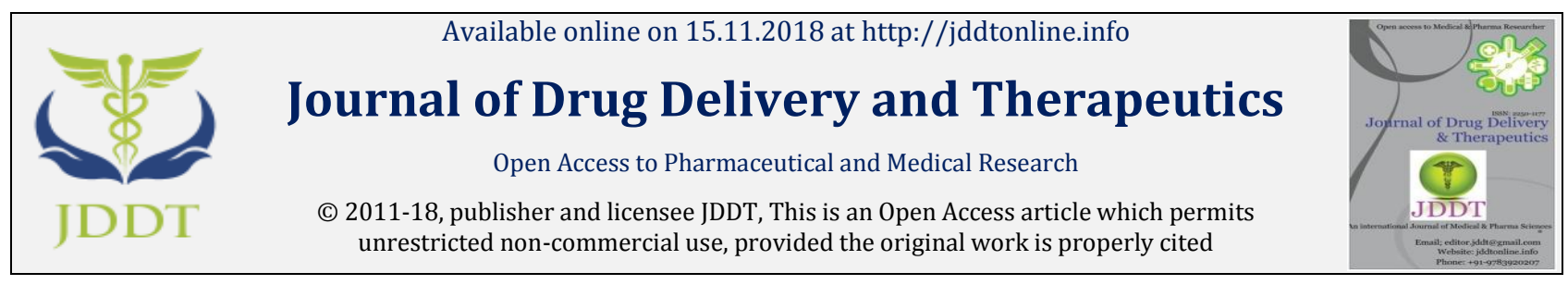

Open 2 Access

Review Article

\title{
Biomedical Nanomaterials: A Short Insight of Applications
}

\author{
Gurpreet Singh *, Preet Mohinder Singh Bedi, Abdul Faruk
}

Department of Pharmaceutical Sciences, Guru Nanak Dev University, Amritsar, Punjab-143005, India

\begin{abstract}
Nanotechnology is rapidly expanding area in the field of science that helps us to manipulate matter at the atomic and molecular level thus having varied and new properties with huge potential. It is the study of extremely small particles ranging from 1 -1000 nm. This small size imparts the nanoscale devices their applications in medicine and physiology while permitting them to interact with cells and tissues at subcellular level, with bioreceptors on both the surface and inside of cell membrane thus providing a high degree of functional specificity to the systems. Nanodevices in medicine involves applications of nanoparticles, polymeric micelles, dendrimers, nanotubes, inorganic nanoparticles, nanocrystals and quantam dots which are currently under development as well as constitute the major part of longer range research. Improvement in drug solubility, high drug loading capacity, ease of surface modification, increase in blood circulation time, controlled release and highly site-specific targeted delivery are the advantages responsible for such wide applications of these nanomaterials. The applications include drug and gene delivery to specific site, delivery and detection of specific proteins, biological imaging and biosensors, DNA probing, tissue engineering, pathogens and tumor detection. This article has made an attempt to cover the few insights of nanotechnology as an interesting approach and illustrates various nanosystems along with their advantages, applications and well approved commercially available products.
\end{abstract}

Keywords: Polymeric micelles, Dendrimers, Nanotubes, Inorganic nanoparticles, Nanocrystals and Quantam dots

Article Info: Received 28 Sep, 2018; Review Completed 27 Oct 2018; Accepted 29 Oct 2018; Available online 15 Nov 2018

Cite this article as:

Singh G, Bedi PMS, Faruk A, Biomedical Nanomaterials: A Short Insight of Applications, Journal of Drug Delivery and Therapeutics. 2018; 8(6): 304-309 DOI: http://dx.doi.org/10.22270/jddt.v8i6.2020

*Address for Correspondence:

Gurpreet Singh, Department of Pharmaceutical Sciences, Guru Nanak Dev University, Amritsar Punjab-143005, India.

\section{INTRODUCTION}

Nanotechnology is the branch of science which deals with the study of design, creation, synthesis and précised manipulation of matter at a nano scale 1 . The word "nano" is derived from the Greek word "dwarf". One nanometer $(\mathrm{nm})$ is a unit in metric system which is equal to one billionth of a meter $\left(10^{-9} \mathrm{~m}\right)^{2}$. At this size, nano materials can have different and enhanced properties compared with larger size of the same material. The nanoparticles (NPs) are nanostructure particles in the size ranging from 1-1000 $\mathrm{nm}$. They provide a variety of surprising and interesting uses in biomedicine by overcoming the many biological and biomedical barriers ${ }^{3}$.

\section{POLYMERIC MICELLES}

The earliest concept of polymeric micelles (PM) was first introduced in 1984 by Ringsdorf et al for drugs having low solubility 4 . They are self-assembled nanostructures micelles ranges from 10 to $200 \mathrm{~nm}$, made up from amphiphilic block copolymers in aqueous solution ${ }^{5}$ as represented in Figure: 1. The formation of micelles starts at critical micelle concentration (CMC) of copolymer in aqueous solution. The non-polar part of block copolymers combine to form a core-shell structure. Thus, the processes of micelles formation take place by decrease in free energy of system 6 .

Polymeric micelles have a great potential to encapsulate a drug which exhibit poor water solubility and low bioavailability. In polymeric micelles, the drugs are encapsulated by various methods such as dialysis method ${ }^{7}$, solvent evaporation method ${ }^{8,9}$ and solid dispersion method10. Other methods mentioned in literatures are direct dissolution ${ }^{11}$, and interpolymer complexation ${ }^{12}$. Most of micelles based formulations are in final stage of clinical trials \& under consideration of FDA. Already FDA approved products includes Cernevit ${ }^{\mathrm{TM}}-12$ (1999) as a multivitamin Intravenous infusion and Estrasorb ${ }^{\mathrm{TM}}$ (1975) for menopause problems as topical formulation ${ }^{13}$. The overall ability of polymeric micelles is dependent upon the interaction of hydrophobic segment and the polarity of drug molecule. Commonly used hydrophobic polymers are selected on the basis of their biocompatibility and nontoxicity. These includes Pluronics ${ }^{\circledR}{ }^{14}$; poly (esters) ${ }^{15}$, poly( $\varepsilon$-caprolactone) ${ }^{16}$ and phospholipids and lipidderivatives. Their therapeutic potential includes the
CODEN (USA): JDDTAO 
delivery of antitumor drugs alone or as a conjugate to specific site ${ }^{17}$. Other advantages includes, stable than surfactant, prolong blood circulation times and protection from mononuclear phagocytic system ${ }^{18}$.

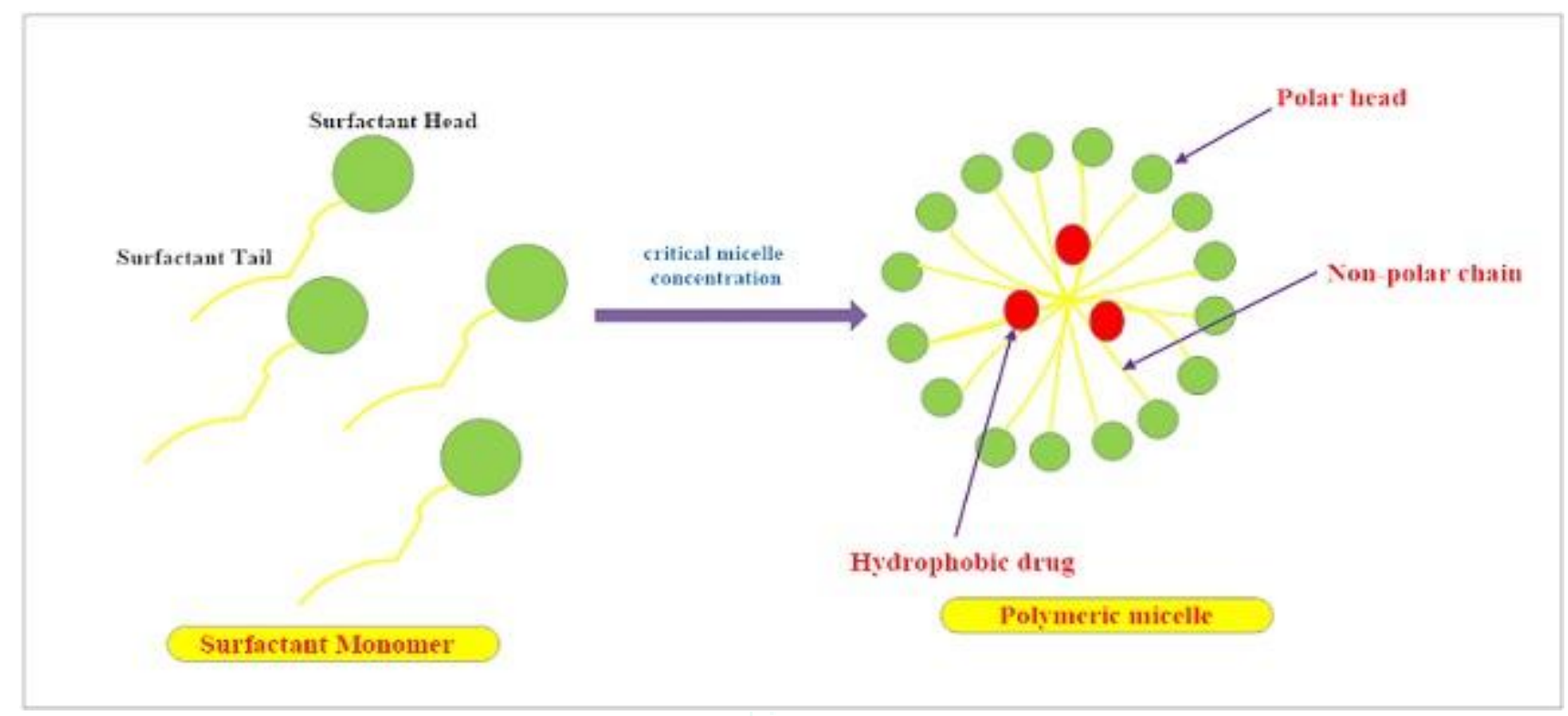

Figure 1: Schematic representation of formation of polymeric micelles

\section{DENDRIMERS}

Dendrimers are polymer-based tree-like, star-shaped macromolecules with doubles or triples branching units as reported by Vogtle et al in $1978^{19}$. They are also known as "arboróis", "cascade molecules" and polymers of the $21^{\text {st }}$ century ${ }^{20}$. They have great potential in biomedical research with ease of modification, simple preparation method and size ranged 2 to $10 \mathrm{~nm}$ for drug targeting. Modification in degree of branching may offer encapsulation possibility for variety of drug molecules ${ }^{21}$. They have a unique architectural design with high degree of branching with internal hydrophobicity suitable for hydrophobic drug as shown in Figure 2.



(A)

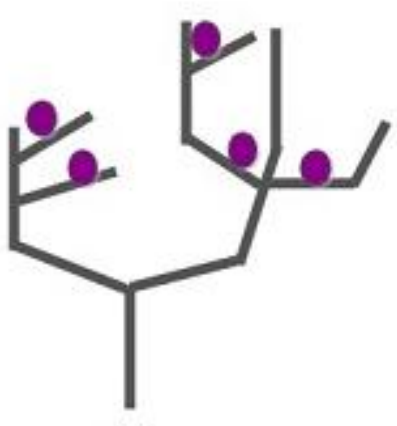

(B)

Figure 2: Schematic representation of dendrimers branching system (A) drug attached terminal surface (B) drug attached to interior terminal branches

Dendrimers consisted of an initiator core, interior layer and layer for terminal functional group attached. Preparation starts from attachment of carbon and other elements to an atom like nitrogen followed by repeated addition of branching molecules by certain chemical reactions. They are three dimensional carrier systems with many functional surface groups; drug can attach to the interior or attached to the surface of dendrimers. The association of drug with dendrimers takes place by physical entrapment, covalent linkage to the surface or as drug conjugates ${ }^{22}$. The resulting dendrimers have the size which is suitable for blood circulation. They can be synthesized and designed into variety of structures due to their feasible topology, functionality and dimensions, ideal for intravenous, oral, transdermal, pulmonary and ocular routes administration ${ }^{23}$. They are ideally used for delivery of oligonucletide, specific receptor site drug targeting, and also for less water soluble drugs ${ }^{24}$. The overall properties of dendrimers are affected by $\mathrm{pH}$, salt effect, nature of solvent and concentration of dendrimer ${ }^{25}$. Examples of dendrimer based products in market are VivaGel ${ }^{\circledR}$ BV, Priostar $\AA$, Stratus CS $\AA$, Starburst $\AA$, Priofect $\AA$ and SuperFect ${ }^{21}$. 


\section{Advantages of dendrimers ${ }^{26,27}$}

1. Size range from $1-100 \mathrm{~nm}$ can overcome the problem of uptake by reticulum endothelium.

2. Lower polydispersity index

3. Outer surface can be utilized for attachment of vector devices for drug targeting

4. Can be prepared for stimuli responsive drug release system

5. Better enhanced permeability and retention effect, can be effectively used for tumour targeting

\section{NANOTUBES}

Carbon nanotubes (CNT) are nanostructure carrier systems that have high drug loading potential and with high cell penetration properties. They can act as a drug container, because of their tube like structure which is made up from one or more layers of grapheme. Sumio Iijima, a Japanese physicist invent the carbon nanotubes in 1991 and received a number of prestigious awards and recognition for his work ${ }^{28}$. Carbon nanotubes are classified as single-walled nanotubes (SWNT) and multi walled carbon nanotubes (MWNTs) as shown in Figure 3. They have been proven for better bioavailability, decreased toxicity and sustained half-life ${ }^{29}$. Carbon nanotubes have numerous biomedical applications and ideal carries for the delivery of proteins. The major focused area of carbon nanotubes is delivery of anticancer agents due to their unique needle-like shapes which enable them to adsorb or covalently bind to the target cell such as delivery of doxorubicin, camptothecin, carboplatin, cisplatin and paclitaxel ${ }^{30}$.

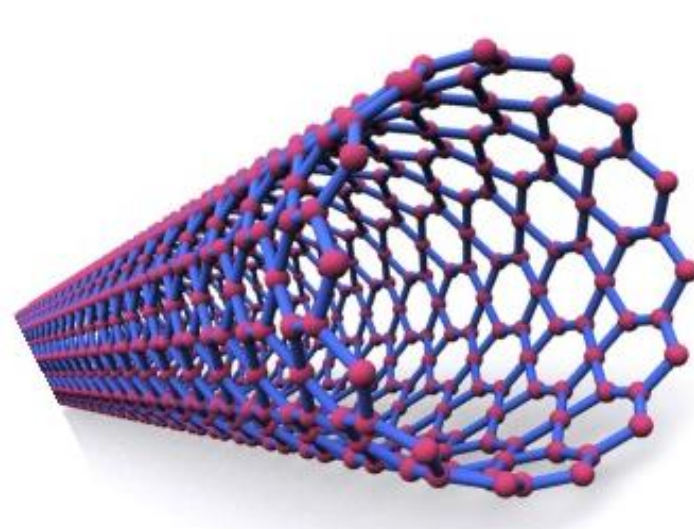

(a) Single-walled nanotubes (SWNT)

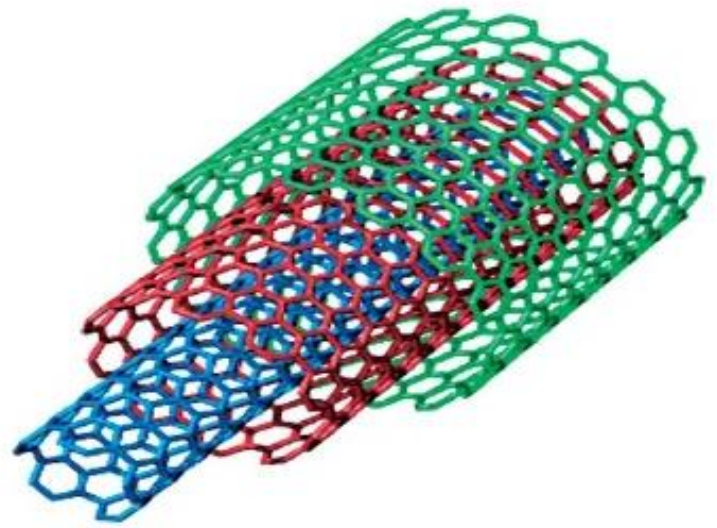

(b) Multi walled carbon nanotubes (MWNTs)

Figure 3: Schematic representation of (a) single-walled nanotubes (SWNT) and (b) multi walled carbon nanotubes (MWNTs)

Due to their high surface area to volume ratio, they provide a good platform for better loading of various drugs and chemicals ${ }^{30}$, 31. The recent biomedical applications of carbon nanotubes are represented in Figure 4.



Figure 4: Application of functionalized carbon nanotubes 


\section{INORGANIC NANOPARTICLES}

Inorganic nanoparticles are commonly used for cellular delivery of gene and protein based drugs. Most inorganic nanoparticles belongs to metals (gold, silver), metal salts and metal oxides with chemical or biological modification for their cellular delivery ${ }^{32}$. They are biocompatibility, and have affinity for different bio-molecules and thus sitespecificity ${ }^{33}$. Gold nanoparticles are considered as potential carrier for intracellular targeting vector due size range of 0.8 and $200 \mathrm{~nm}$, surface modification and possess visible light extinction behavior for drug tracking purpose in the cells. Similarly, silver nanoparticles have gained the attention with unique properties to develop products for medical and industrial purposes. They have ideal optical, electrical and thermal properties that have impact on their application in medical device, optical sensors and in drug delivery systems ${ }^{10}, 34$,

\section{Advantages of inorganic nanoparticle $32,35,36$}

1. Ease of surface modification and conjugation based on various structures and nature of drugs

2. High loadings capacity

3. Controlled release kinetics based on the material or capping method

4. Provide protection from various factors until not released, hence improved the in vivo bioavailability

5. Suitable for magnetically or antibody-targeted targeted delivery to specific tissue or sites.

6. Can be use as biomarkers in the diagnosis of heart diseases, cancers, and other conditions

7. Suitable for biological imaging and biosensors applications

8. Use as probes for microscopy such as transmission electron microscopy

\section{NANOCRYSTALS}

Nanocrystals are crystalline aggregates of the drugs surrounded by a thin coating of hydrophilic layer of surfactant. The hydrophilic layer helps in drug biodistribution and bioavailability and control the aggregation of the crystalline drug material during storage 35 . The concept of formation of nanocrystal is extensively evolved for solubility enhancement. Nanocrystal technology improved dissolution rate, high drug loading, improved oral absorption and bioavailability ${ }^{37}$. Commonly used methods for preparation of nanocrystals are nanoprecipitation, milling, homogenization ${ }^{38}$, Spray drying ${ }^{39}$, Nanopure ${ }^{\circledR}$ XP technology ${ }^{40}$ and Spray Freezing into Liquid technology ${ }^{41}$.

\section{Advantages of nanocrystals 42}

1. Improved rate of absorption

2. Increased over all surface area

3. Enhanced solubility

4. Increased the rate of dissolution

5. Suitable for various administration routes
6. Further processing in various dosages form such as tablets, capsules

7. Increased blood circulation time

8. Can be formulate as hybrid nanocrystals for both diagnostic and therapeutic purpose

\section{QUANTUM DOTS}

Quantum dots are semiconducting nanoparticles being illuminated by light and characteristically used for bioimaging applications. They present many intrinsic photophysical properties that are desirable for the imaging and drug targeting purposes. Quantum mean amount, a discrete unit commonly used to represent change in energy or matter involved in an interaction ${ }^{43}$. Quantum dots generally have metalloid crystalline core which are enclosed by a shell and when exposed to ultraviolet light, they emit the signal of visible light which can determine a image of source 44 . Quantum dots are 20-100 times brighter than traditionally used dyes for in vitro imaging 45 . They play a vital role in investigation of intracellular moment of nanosized structures coupled with help of confocal microscopy or transmission electron microscopy. Quantum dots are ideal tool for in vivo animal imaging but limited in human studies due to heavy metal toxicity 46 . Major applications of quantum dots includes, labeling cells, neural imaging, lymph node mapping, vasculature imaging, use as biomarkers for cancer detection, photodynamic cancer therapy, and as a delivery systems ${ }^{45,47 \text {. }}$

\section{Advantages of quantum dots ${ }^{43}$}

1. Longer-lasting photostability

2. Broader excitation spectra and a well defined emission peak

3. More stable than organic dyes

4. Can be modified with biomaterials

5. Better contrast for electron microscope

6. Real-time tracking of molecules and cells

7. Easy to make and produce several different colors

\section{CONCLUSION}

Nanomaterials have unique physicochemical and biological properties which help to overcome the limitations of other conventional dosage forms. It has been gaining a widespread popularity due to its promising usage in disease diagnosis and treatment with high efficacy as no data is available about its any harmful effect to the best of our knowledge. The advantageous properties are basically due to their peculiar size and shape which accounts for the high attention of researchers for their use towards every aspect of human health. Thus, nanotechnology is revolutionizing the advances in medicine and research both in laboratories and clinically.

Conflicts of Interest: Nil

Acknowledgment: Nil 


\section{REFERENCES}

1. Albanese A, Tang PS, Chan WC. The effect of nanoparticle size, shape, and surface chemistry on biological systems. Annual review of biomedical engineering. 2012; 14:1-16. PubMed PMID: 22524388

2. Toumey C. Why not zwergo-technology? Nature nanotechnology. 2011; 6(7):393-4. PubMed PMID: 21731067.

3. Wong IY, Bhatia SN, Toner M. Nanotechnology: emerging tools for biology and medicine. Genes \& development. 2013; 27(22):2397-408. PubMed PMID: 24240230. Pubmed Central PMCID: 3841729.

4. Bader H, Ringsdorf H, Schmidt B. Watersoluble polymers in medicine. Die Angewandte Makromolekulare Chemie. 1984; 123(1):457-85

5. Riess G. Micellization of block copolymers. Progress in Polymer Science. 2003; 28(7):1107-70.

6. Jones M, Leroux J. Polymeric micelles - a new generation of colloidal drug carriers. Eur J Pharm Biopharm. 1999; 48(2):101-11. PubMed PMID: 10469928.

7. Van Butsele K, Sibret P, Fustin CA, Gohy JF, Passirani C, Benoit $\mathrm{JP}$, et al. Synthesis and $\mathrm{pH}$-dependent micellization of diblock copolymer mixtures. Journal of colloid and interface science. 2009; 329(2):235-43. PubMed PMID: 18930246.

8. Taillefer J, Jones MC, Brasseur N, van Lier JE, Leroux JC. Preparation and characterization of $\mathrm{pH}$-responsive polymeric micelles for the delivery of photosensitizing anticancer drugs. Journal of pharmaceutical sciences. 2000; 89(1):52-62. PubMed PMID: 10664538 .

9. Lavasanifar A, Samuel J, Kwon GS. Micelles self-assembled from poly(ethylene oxide)-block-poly(N-hexyl stearate Laspartamide) by a solvent evaporation method: effect on the solubilization and haemolytic activity of amphotericin B. Journal of controlled release : official journal of the Controlled Release Society. 2001; 77(1-2):155-60. PubMed PMID: 11689268.

10. Zhang X, Jackson JK, Burt HM. Development of amphiphilic diblock copolymers as micellar carriers of taxol. International journal of pharmaceutics. 1996; 132(1):195-206.

11. Burt HM, Zhang $X$, Toleikis $P$, Embree L, Hunter WL. Development of copolymers of poly(d,l-lactide) and methoxypolyethylene glycol as micellar carriers of paclitaxel. Colloids and Surfaces B: Biointerfaces. 1999; 16(1):161-71.

12. Lefevre N, Fustin CA, Gohy JF. Polymeric micelles induced by interpolymer complexation. Macromol Rapid Commun. 2009 Nov 19; 30(22):1871-88. PubMed PMID: 21638469.

13. CenterWatch: Clinical Research and Drug Information, https://www.centerwatch.com/ accessed on 22/8/2018

14. Rapoport N. Combined cancer therapy by micellarencapsulated drug and ultrasound. International journal of pharmaceutics. 2004; 277(1-2):155-62. PubMed PMID: 15158978.

15. Ruan G, Feng SS. Preparation and characterization of poly(lactic acid)-poly(ethylene glycol)-poly(lactic acid) (PLAPEG-PLA) microspheres for controlled release of paclitaxel. Biomaterials. 2003; 24(27):5037-44. PubMed PMID: 14559017.

16. Krimmer SG, Pan H, Liu J, Yang J, Kopecek J. Synthesis and characterization of poly(epsilon-caprolactone)-block-poly[N(2-hydroxypropyl)methacrylamide] micelles for drug delivery. Macromolecular bioscience. 2011; 11(8):1041-51. PubMed PMID: 21567954. Pubmed Central PMCID: 4598047.

17. Woodle MC, Engbers CM, Zalipsky S. New amphipatic polymer-lipid conjugates forming long-circulating reticuloendothelial system-evading liposomes. Bioconjugate chemistry. 1994; 5(6):493-6. PubMed PMID: 7873652.

18. Oerlemans C, Bult W, Bos M, Storm G, Nijsen JF, Hennink WE. Polymeric micelles in anticancer therapy: targeting, imaging and triggered release. Pharmaceutical research. 2010; 27(12):2569-89. PubMed PMID: 20725771. Pubmed Central PMCID: 2982955.

19. Buhleier E, Wehner W, VÖGtle F. "Cascade"- and "NonskidChain-like" Syntheses of Molecular Cavity Topologies. Synthesis. 1978; 1978(02):155-8. En.

20. Newkome GR, Baker GR, Young JK, Traynham JG. A systematic nomenclature for cascade polymers. Journal of Polymer Science Part A: Polymer Chemistry. 1993; 31(3):641-51.
21. Choudhary S, Gupta L, Rani S, Dave K, Gupta U. Impact of Dendrimers on Solubility of Hydrophobic Drug Molecules. Frontiers in pharmacology. 2017; 8:261. PubMed PMID: 28559844. Pubmed Central PMCID: 5432624.

22. Palmerston Mendes L, Pan J, Torchilin VP. Dendrimers as Nanocarriers for Nucleic Acid and Drug Delivery in Cancer Therapy. Molecules. 2017; 22(9). PubMed PMID: 28832535. Pubmed Central PMCID: 5600151.

23. Cheng, C. M., \& Wu, K. C. Nanomaterials and nanofabrication for biomedical applications. Sci Technol Adv Mater, 2013; 14(4):040301.

24. Madaan K, Kumar S, Poonia N, Lather V, Pandita D. Dendrimers in drug delivery and targeting: Drug-dendrimer interactions and toxicity issues. Journal of pharmacy \& bioallied sciences. 2014; 6(3):139-50. PubMed PMID: 25035633. Pubmed Central PMCID: 4097927.

25. Maiti PK, Çağın T, Lin S-T, Goddard WA. Effect of Solvent and $\mathrm{pH}$ on the Structure of PAMAM Dendrimers. Macromolecules. 2005; 38(3):979-91.

26. Nanjwade BK, Bechra HM, Derkar GK, Manvi FV, Nanjwade VK. Dendrimers: Emerging polymers for drug-delivery systems. European Journal of Pharmaceutical Sciences. 2009 2009; 38(3):185-96.

27. Kalomiraki M, Thermos $\mathrm{K}$, Chaniotakis NA. Dendrimers as tunable vectors of drug delivery systems and biomedical and ocular applications. International journal of nanomedicine. 2016; 11:1-12. PubMed PMID: 26730187. Pubmed Central PMCID: 4694674.

28. Rastogi V, Yadav P, Bhattacharya SS, Mishra AK, Verma N, Verma A, et al. Carbon nanotubes: an emerging drug carrier for targeting cancer cells. Journal of drug delivery. 2014; 2014:670815. PubMed PMID: 24872894. Pubmed Central PMCID: 4020363.

29. Yan Y, Chan-Park MB, Zhang Q. Advances in carbon-nanotube assembly. Small. 2007; 3(1):24-42. PubMed PMID: 17294465.

30. Son KH, Hong JH, Lee JW. Carbon nanotubes as cancer therapeutic carriers and mediators. International journal of nanomedicine. 2016; 11:5163-85. PubMed PMID: 27785021. Pubmed Central PMCID: 5066859.

31. Alshehri R, Ilyas AM, Hasan A, Arnaout A, Ahmed F, Memic A. Carbon Nanotubes in Biomedical Applications: Factors, Mechanisms, and Remedies of Toxicity. Journal of medicinal chemistry. 2016; 59(18):8149-67. PubMed PMID: 27142556.

32. Bayda S, Hadla M, Palazzolo S, Corona G, Toffoli G, Rizzolio F. Inorganic Nanoparticles for Cancer Therapy: a Transition from Lab to Clinic. Current medicinal chemistry. 2017 Dec 29. PubMed PMID: 29284391.

33. Yeh YC, Creran B, Rotello VM. Gold nanoparticles: preparation, properties, and applications in bionanotechnology. Nanoscale. 2012; 4(6):1871-80. PubMed PMID: 22076024. Pubmed Central PMCID: 4101904.

34. Wei L, Lu J, Xu H, Patel A, Chen ZS, Chen G. Silver nanoparticles: synthesis, properties, and therapeutic applications. Drug discovery today. 2015; 20(5):595-601. PubMed PMID: 25543008. Pubmed Central PMCID: 4433816.

35. Wang F, Li C, Cheng J, Yuan Z. Recent Advances on Inorganic Nanoparticle-Based Cancer Therapeutic Agents. Int J Environ Res Public Health. 2016; 13(12). PubMed PMID: 27898016. Pubmed Central PMCID: 5201323.

36. Anselmo AC, Mitragotri S. A Review of Clinical Translation of Inorganic Nanoparticles. The AAPS journal. 2015; 17(5):1041-54. PubMed PMID: 25956384. Pubmed Central PMCID: 4540735.

37. Thakkar S, Shah V, Misra M, Kalia K. Nanocrystal Based Drug Delivery System: Conventional and Current Scenario. Recent patents on nanotechnology. 2017; 11(2):130-45. PubMed PMID: 27758683.

38. de Waard H, Frijlink HW, Hinrichs WL. Bottom-up preparation techniques for nanocrystals of lipophilic drugs. Pharmaceutical research. 2011; 28(5):1220-3. PubMed PMID: 21086152. Pubmed Central PMCID: 3073053.

39. Hou Y, Shao J, Fu Q, Li J, Sun J, He Z. Spray-dried nanocrystals for a highly hydrophobic drug: Increased drug loading, enhanced redispersity, and improved oral bioavailability. International journal of pharmaceutics. 2017; 516(1):372-9. 
40. Rogers TL, Hu J, Yu Z, Johnston KP, Williams RO, 3rd. A novel particle engineering technology: spray-freezing into liquid. International Journal of pharmaceutics. 2002; 242(1-2):93100. PubMed PMID: 12176230.

41. Junghanns JU, Muller RH. Nanocrystal technology, drug delivery and clinical applications. Int J Nanomedicine. 2008; 3(3):295-309. PubMed PMID: 18990939. Pubmed Central PMCID: 2626933.

42. Gigliobianco MR, Casadidio C, Censi R, Di Martino P. Nanocrystals of Poorly Soluble Drugs: Drug Bioavailability and Physicochemical Stability. Pharmaceutics. 2018; 10(3). PubMed PMID: 30134537. Pubmed Central PMCID: 6161002.

43. Bajwa N, Mehra NK, Jain K, Jain NK. Pharmaceutical and biomedical applications of quantum dots. Artificial cells, nanomedicine, and biotechnology. 2016; 44(3):758-68. PubMed PMID: 26058404
44. Chan WC, Nie S. Quantum dot bioconjugates for ultrasensitive nonisotopic detection. Science. 1998; 281(5385):2016-8. PubMed PMID: 9748158.

45. Walling MA, Novak JA, Shepard JR. Quantum dots for live cell and in vivo imaging. International journal of molecular sciences. 2009; 10(2):441-91. PubMed PMID: 19333416. Pubmed Central PMCID: 2660663.

46. Cai W, Hsu AR, Li ZB, Chen X. Are quantum dots ready for in vivo imaging in human subjects? Nanoscale Res Lett. 2007; 2(6):265-81. PubMed PMID: 21394238. Pubmed Central PMCID: 3050636.

47. Pohanka M. Quantum Dots in the Therapy: Current Trends and Perspectives. Mini reviews in medicinal chemistry. 2017; 17(8):650-6. PubMed PMID: 28117021.

\section{About the Authors:}

\section{Gurpreet Singh}

Department of Pharmaceutical Sciences, Guru Nanak Dev University, Amritsar Punjab-143005, India.

ORCID ID: http://orcid.org/0000-0001-5436-2697,

Researcher ID: D-9909-2014,

Scopus Author ID: 56166600300

E-mail: gurpreet_pharma85@yahoo.com,

Mobile: +91-9814085601

\section{Prof. Preet Mohinder Singh Bedi}

Head, Department of Pharmaceutical Sciences, Guru Nanak Dev University, Amritsar, Punjab 143005, India

E-mail: bedi_preet@yahoo.com

Mobile: +91-9815698249

\section{Dr. Abdul Faruk}

Presently, Head, Department of Pharmaceutical Sciences, HNB Garhwal University (A Central University) Chauras Campus, P.O. Kilkeleshwar, Via Kirtinagar Distt. Tehri Garhwal-249161 Uttrakhand E-mail: abdul_faruk@yahoo.com

Email: abdul_faruk@yahoo.com Mobile: +91-9412079188,+91-9456348123 